\title{
How can DCTs become involved in research?
}

\author{
By J. Shelswell and V. A. Patel, Leeds, UK
}

As a dental core trainee (DCT), opportunities to actively participate in large research studies are limited.

This article describes the experiences of two academic DCT3s.

The key attractions of these academic posts are:

- To work on research projects embedded within an established research group

- To undertake a funded PG Cert in Health Research

- Four days a week standard DCT3 clinical training.

\section{Academic DCT posts}

We currently work as DCT3s in Restorative Dentistry (Post 1) and Oral Medicine, Oral Pathology, Oral Radiology (Post 2) at the Leeds Dental Institute. As part of these posts, we have one day a week of protected time to develop our academic skills. Of the 77 DCT3 posts available in 2019 , only two included specific academic duties within their roles. ${ }^{1} \mathrm{We}$ actively sought these posts when applying for DCT3, since the nature of DCT rotations and national recruitment make it very difficult to sustain an active role embedded within a large research project. Given the significant academic activity included in specialty training, as well as the drive to increase research undertaken in primary care, ${ }^{2,3}$ we believe an increase in the number of academic DCT posts would benefit postgraduate trainees and the future wider workforce.

\section{How did we become involved in the PLATOON study?}

Our academic time is spent supporting a British Orthodontic Society-funded study: Premature Loss of bAby Teeth and its impact On Orthodontic Need (PLATOON). ${ }^{4}$ This cross-sectional study is the first to investigate the impact of premature extraction of primary teeth on orthodontic need in a longitudinal cohort. The study is working with the Born in Bradford (BiB) birth cohort. ${ }^{5}$

We are involved in collecting orthodontic records for each child, including dental charting, photographs and impressions. These records are assessed by orthodontists to determine any space loss and the patient's orthodontic needs using the Index of Orthodontic Treatment Need (IOTN). The study is planning to collect similar data in the permanent dentition to assess the accuracy of the IOTN predictions.

Before our first data collection days, we completed Good Clinical Practice training to develop an understanding about research standards. Each day involves visiting a primary school in Bradford and dividing a school room into an area where children watch an introductory video and complete an oral health-related quality of life questionnaire and an area where clinical records are collected (Fig. 1).

The team (Fig. 2) includes a project lead who maintains oversight of day-to-day data collection, ensuring consent forms are present and any incidents are appropriately managed. A dental therapist leads the process of gathering clinical records alongside a dental nurse. Our role involves identifying the correct child, explaining the process and helping participants complete the questionnaire. We also assist with dental charting, confirming whether a child falls into the exposure (has had an extraction of primary tooth/teeth) or control

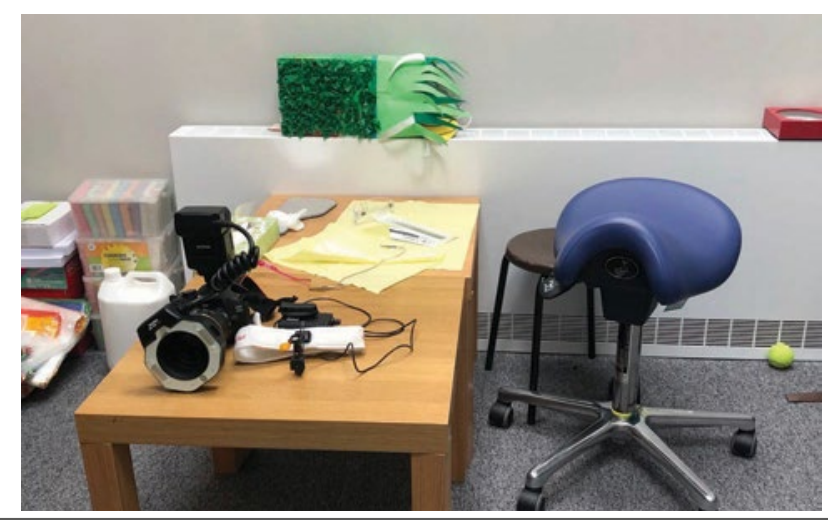

Fig. 1 A school clinic to collect orthodontic records

(non-extraction) arm of the study, and sending letters to parents if concerns are noted during the examination. Our role also includes quality assurance, ensuring all procedures are followed, and records are fully completed for each participant.

\section{What have we learnt about research?}

Our involvement has allowed us to learn about the practicalities of research. A major hurdle has been ensuring adequate parent response to consent forms to make sure sufficient participants are recruited. It is apparent that the wider research team have worked very hard to engage with schools. A short film has been developed in English and Urdu to help parents and children understand what the research involves. ${ }^{6}$ It is not uncommon for parents to choose not to consent for extraoral photographs and some children cannot tolerate impressions, presenting challenges when only incomplete records are collected. We regularly meet with orthodontic colleagues who will oversee the assessment of the orthodontic records. This has highlighted the importance of communication across the entire research team to achieve appropriate data collection. Another insight has been the complexity of undertaking research, for example the amount of equipment that needs to be transported to schools. Our data collection is underpinned by risk assessments and standard operating procedures to ensure safe and effective delivery.

Although our time with the PLATOON study has been too short to collate the major findings, the experience has nevertheless proved invaluable. It has taught us about the foundations of research, as well as the realities of data collection in schools. Our academic 


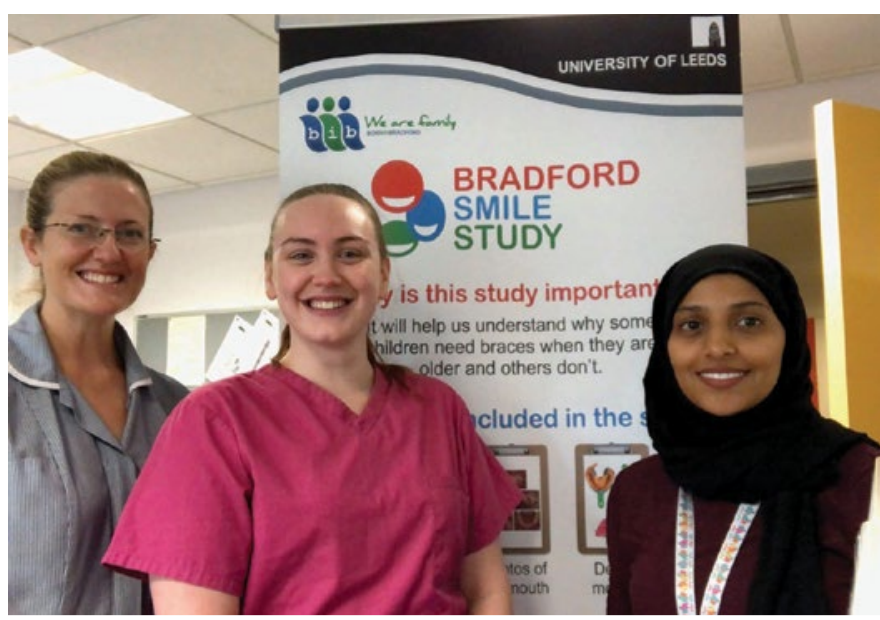

Fig. 2a Members of the research team

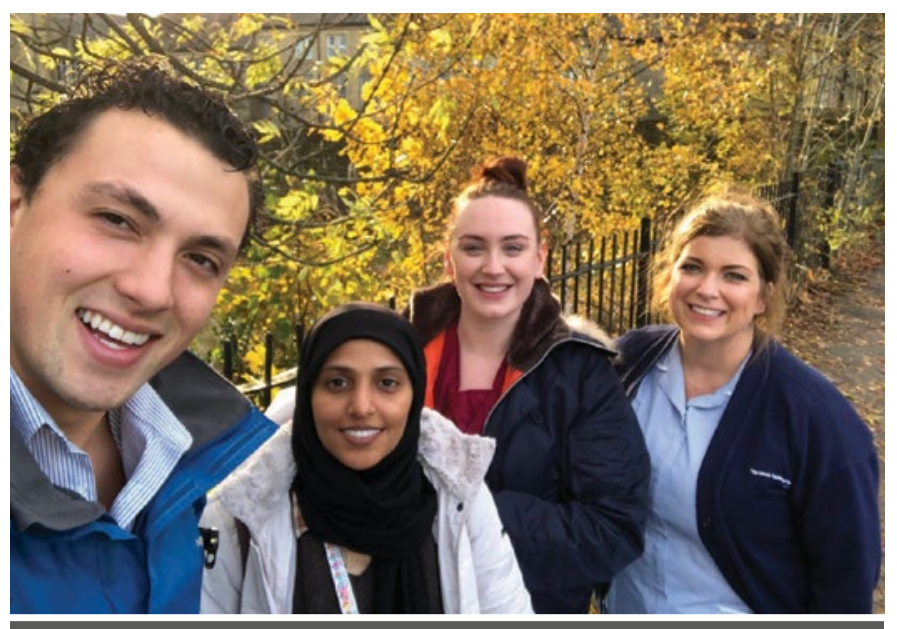

Fig. $2 \mathrm{~b}$ Members of the research team
4 DCT posts will motivate us to continue to actively participate in research and academic dentistry later in our careers.

The PLATOON study was discussed in a recent Radio 4 documentary?

\section{Acknowledgements}

We would like to thank all the wider research team for providing us with this opportunity - Eman Alnuaimi, Annalea Staples, Louise Dell'Amico, Anna Nielsen, Zubeda Khatoon, Minnie Lyons-Coleman, Lucy Brown, Simon Littlewood, Sophy Barber, Peter Day.

$B i B$ is only possible because of the enthusiasm and commitment of the children and parents in BiB. We are grateful to all the participants, health professionals and researchers who have made BiB happen.

\section{References}

1. Health Education England East Midlands. National Dental Core Training (DCT) Recruitment 2020. Available at: https://www.eastmidlandsdeanery.nhs.uk/recruitment/dental/dental_core_training (accessed November 2019).

2. FGDP(UK). Research. Available at: https://www.fgdp.org.uk/research (accessed November 2019).

3. Heasman $\mathrm{P}$, Macpherson $\mathrm{L}$, Haining $\mathrm{S}$ et al. Clinical research in primary dental care. $\mathrm{Br}$ Dent J 2015; 219: 159-163.

4. Brown L R, Barber S, Benson P E et al. PLATOON: Premature Loss of bAby Teeth and its impact On Orthodontic Need - protocol. J Orthod 2019; 46: 118-125.

5. Bird P K, McEachan R R C, Mon-Williams M et al. Growing up in Bradford: protocol for the age 7-11 follow up of the Born in Bradford birth cohort. BMC Public Health 2019; 19: 939.

6. Leeds School of Dentistry. Bradford Smile Study (URDU). Available at: https://www. youtube.com/watch?v=EwHQKqwQH9Q (accessed December 2019).

7. BBC Radio 4. Born in Bradford. Available at: https://www.bbc.co.uk/programmes/ m0009kt4 (accessed February 2020).

\section{Celebrating 100 years of the BDA library}

On 6 February dentists, librarians and British Dental Association (BDA) staff gathered to celebrate 100 years of the BDA library, known officially as the 'Robert and Lilian Lindsay Library'.

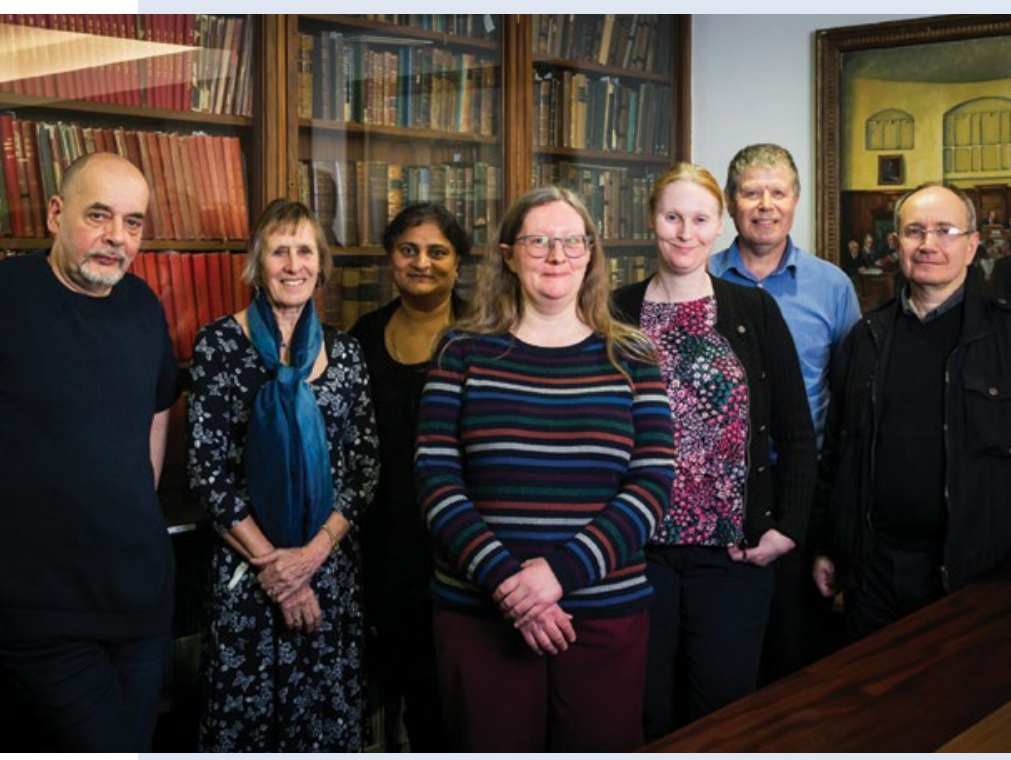

Current BDA Library staff celebrating with former Heads of the Library Margaret Clennett (second left) and Roger Farbey (far right) and former Assistant Librarian Julian Roland (second right)
Amongst those attending was Edwina Brugge, Lilian Lindsay's great great niece, along with her daughter and husband. Lilian Lindsay, the first woman to qualify as a dentist in the UK, was the BDA's first librarian and served in the capacity of honorary librarian for 40 years.

BDJ Editor-in-Chief Stephen Hancocks, Lindsay Society President Roland Hopwood and current Head of the BDA library Helen Nield gave a 'dramatic' presentation of letters and memoirs, painting a picture of Dr Lindsay's character. This was followed by a speech from BDA President Roz McMullan describing the long history of the library and its immense contribution past and present to supporting dentists and dental students with their learning and development through a range of changing technologies.

A cake featuring a photograph of the three homes of the library at Russell Square, Hill Street and Wimpole Street was then cut by the current and two previous heads of the library, Helen Nield, Roger Farbey and Margaret Clennett. Visitors were presented with a commemorative centenary booklet and had the opportunity to view an exhibition in the foyer area showing the library through the ages. This exhibition is on until the end of April.

Commenting afterwards Helen Nield said 'Continuing professional development is such an important part of being a dentist and the library has been here since 1920 supporting the profession in its quest for knowledge and will hopefully continue to do so over the next 100 years!' 